\title{
Awareness of Unsafe Abortion among the Reproductive Age Women in a Tertiary Level Hospital in Sylhet, Bangladesh
}

Sufia Khatun $(\mathrm{RN}, \mathrm{MPH})^{1}$, Prof. Dr. Gol Baden $(\mathrm{RN}, \mathrm{PhD})^{2}$, Rashed Ullah Rana (RN, MPH) ${ }^{3^{*}}$, Sulaka Akter $(\mathrm{RN}$, $\mathrm{MPH})^{4}$, Ila Sinha $(\mathrm{RN}, \mathrm{MPH})^{5}$, Tajul Islam $(\mathrm{RN}, \mathrm{MSN})^{6}$

${ }_{1,3,45}$ Assistant Professor North-East Nursing College, Sylhet, Bangladesh

${ }^{2}$ Principal, North-East Nursing College, Sylhet, Bangladesh

${ }^{6}$ Senior Staff Nurse, Sylhet Infectious Disease Hospital, Sylhet, Bangladesh

\author{
Article History \\ Received: 12.03 .2021 \\ Accepted: 24.04 .2021 \\ Published: 30.04 .2021 \\ Journal homepage: \\ https://www.easpublisher.com
}

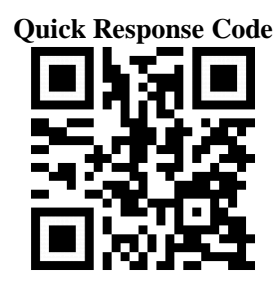

Abstract: Background: Globally, abortion is a leading cause of maternal morbidity and mortality, and often unsafe. Unsafe abortion is one of the serious public health problems faced by the thousands of Bangladeshi woman. However, there is little known awareness about unsafe abortion among reproductive age woman in Sylhet district. Objectives: To assess awareness of unsafe abortion among the reproductive age woman in a tertiary level hospital in Sylhet. Methods: A descriptive cross-sectional study was conducted with a sample size of 130. Data was collected by using a pre-tested and semistructured questionnaire through face to face interview technique. Results: The study findings show that A highly significant association was found knowledge on unsafe abortion with educational qualification of the respondents ( $\mathrm{P}$ value $=$ $0.001)$ and also with monthly income $(\mathrm{P}$ value $=0.004)$. Conclusion: The maternity leave should be establish for all of female person who become pregnant.

Keywords: Abortion, risk, reproductive, unsafe, woman.

Copyright (C) 2021 The Author(s): This is an open-access article distributed under the terms of the Creative Commons Attribution 4.0 International License (CC BY-NC 4.0) which permits unrestricted use, distribution, and reproduction in any medium for non-commercial use provided the original author and source are credited.

\section{INTRODUCTION}

Globally, abortion is a leading cause of maternal morbidity and mortality, and often unsafe. According to World Health Organization statistics, between 2015 and 2019 as estimated approximately of 73.3 million induced (safe and unsafe) abortions occurred worldwide each year [1]. Unsafe abortion accounts for $13 \%$ of maternal deaths worldwide [2]. $45 \%$ of all abortion are unsafe occurs in developing countries [1]. WHO describe, unsafe abortion is a procedure for terminating an unwanted pregnancy either by persons lacking the necessary skills or in an environment lacking the minimal medical standards, or both [1].

Unsafe abortion is one of the serious problems faced by the thousands of Bangladeshi woman. Early marriage, rape, intimate partner violence and unwanted pregnancy are causes of abortion [3-6]. The incidence of abortion and proportion of abortion-related maternal deaths have increased in Bangladesh has found $7 \%$ in 2016 [7]. According to the review, approximately $1,194,000$ induced abortions performed in Bangladesh in the year of 2014 (29 per 1,000 women aged 15-49) [6]. Moreover, based on report of ICDDRB, Bangladesh described that the incidence of abortion was found 35 times higher for unmarried woman in Bangladesh than married adolescents. This ratio also higher among 18 years aged adolescents and who have not completed secondary education [8].

Review show that women between the ages of 35- 49 are $53 \%$ more likely than women between the ages of 15 -19 to have an unsafe induced abortion [9]. In addition, young women between the ages of 15 and 19 had the greatest risk of dying as a result of an abortion-related complication [10]. Induced abortion is illegal in Bangladesh under the penal code of 1860 , unless it is performed to save a woman's life [11]. Most of abortion cases were performed unskilled personnel and conducted in unsafe condition as a result severe medical complication occurs likes hemorrhage, incomplete abortion, cervical laceration, sepsis, uterine perforation, bladder injury and shock.

The main causes of death from unsafe abortion are hemorrhage, infection, sepsis, genital trauma and necrotic bowel. Other immediate consequences of unsafe abortion include loss of productivity and psychological damage. The burden of unsafe aborts lies not only with the women and families, but also within 
the public health system. Even many children victimized for motherless. Every woman admitted for emergency post abortion care may require blood products, antibiotics, oxytocics, anesthesia, operating system, and surgical specialists. The financial and logistical impact of emergency care can overwhelm a healthy system and can prevent attention to be administered to other patients.

The study of abortion literature found that $88.3 \%$ had good knowledge of abortion [12], 27\% to $68.4 \%$ had good knowledge of safe abortion [13-14] and $35.7 \%$ had good awareness of safe abortion [13]. Almost every abortion death and disability could be prevented through sexuality education, use of effective contraception, provision of safe, legal induced abortion, and timely care for complications. Thus, awareness of unsafe abortion is particularly important because of high rate unwanted and teenage pregnancy, sexually transmitted infractions and other diseases. However, there is little known about awareness, about unsafe abortion among reproductive age woman in Sylhet district.

This study expected to reveal a clear picture of existing knowledge and preventive awareness on unsafe abortion. So, this study will be an additional resource for understanding the present status of awareness of unsafe abortion, finding the study will help the planner and policy maker to design programs and intervention so that unsafe abortion can be prevented and thus we can reduce maternal mortality.

\section{OBJectives}

To assess the awareness about unsafe abortion among the reproductive age woman in a tertiary level hospital, Sylhet

\section{Specific Objectives}

1. Assess the socio-demographic of respondent

2. Assess the knowledge and awareness about unsafe abortion

3. See the relationship between socio demographic characteristics and awareness of unsafe abortion.

\section{MeTHOdOLOGY}

A descriptive cross-sectional study was conducted. The study population was all the reproductive aged women of Sylhet district and the sample population of this study was reproductive age woman age between 15-49 years in Sylhet district. This study was conducted in North East Medical College Hospital, South Surma, Sylhet. The study was conducted in the period from September 2013 to December2020.

\section{Sample Size}

The sample size was taken on the basis of following formula.
Sample size $\quad \mathrm{n}=\underset{\mathrm{d}^{2}}{\mathrm{z}^{2} \mathrm{pq}}$

Where,

$\mathrm{n}=$ the minimum sample size

$\mathrm{Z}=$ the standard normal deviate usually set at 1.96 which corresponds to the $95 \% \mathrm{CI}$

The $\mathrm{P}=$ proportion of the target population, $42 \%=$ $0.42 \%$.

$\mathrm{q}=1-0.2=0.50$

$\mathrm{d}=$ desired degree of accuracy considered $=0.05$

By using formula, sample size $n=z^{2} p q / d^{2}$

$=(1.96)^{2} \times 0.42 \times 0.50$

$=312^{(0.05)^{2}}$

$=312$

Due to various limitations we took 130 respondent for this study according to the discion of our advisor panel.

\section{Inclusion criteria}

The respondents were reproductive age groups between 15-49 years and who admitted in North East Medical College Hospital, Sylhet. The respondents were selected those who are willingly interested to participate in this study.

\section{Sampling Technique}

Non-probability purposive sampling technique was add for the study.

\section{Data collection tool}

Data was collected by using pre-tested, modified and semi-structured questionnaire through face to face interview technique.

\section{Data collection Technique \\ By face to face interview.}

\section{Ethical consideration}

A formal permission letter was obtained from authority of North East Medial College Hospital. After explaining the purpose of the study participants, we assured that the information will kept and not disclose to others. They were also informed that have the right to not participate and withdraw without the any excuses. Informed consent was taken from participants.

\section{Data Management and Analysis plan}

Statistical package for social science SPSS) version 16.0 (Chicago) a computer programmed was used for entry and analyze the collected data. The proportion was presented by frequency and cross tabulation analysis. The association was found out by using Pearson Chi-Square $\left(\mathrm{X}^{2}\right)$ test.

\section{Results}

\section{Socio-demographic characteristics of the respondents}

From the total of 130 reproductive aged women involved in the study, $66.9 \%, 27.7 \%$ and $5.4 \%$ 
of the respondents belonged to age group of 15-30 years, 31-45 years and $>45$ years respectively with mean age $29.22 \pm 8.215$ years. Most of them $(84.6 \%)$ were married and few of them $(15.4 \%)$ of were unmarried. The majority of the respondents $(29.2 \%)$ educational qualification level were primary, $23.8 \%$ higher secondary, $22.3 \%$ secondary, $10 \%$ was graduating and above and only $14.6 \%$ found to be illiterate. A great portion of the respondents (54.6\%) monthly income was BDT $<10000,39.2 \%$ BDT $10001-$ 20000 and only $6.2 \%$ of their income were BDT $>20000$ (Table- 1).

Table-1: Socio-demographic characteristics of the respondents

\begin{tabular}{|l|l|l|l|}
\hline Variable & Group & Frequency & Percent (\%) \\
\hline \multirow{3}{*}{$\begin{array}{l}\text { Age } \\
\text { Mean } \pm \text { SD=29.22 } \pm 8.215\end{array}$} & $15-30$ & 87 & 66.9 \\
\cline { 2 - 4 } & $31-45$ & 36 & 27.7 \\
\cline { 2 - 4 } & $>45$ & 7 & 5.4 \\
\hline Marital status & Married & 110 & 84.6 \\
\cline { 2 - 4 } & Unmarried & 20 & 15.4 \\
\hline Qualification & Illiterate & 19 & 14.6 \\
\cline { 2 - 4 } & Primary & 38 & 29.2 \\
\cline { 2 - 4 } & Secondary & 29 & 22.3 \\
\cline { 2 - 4 } & Higher Secondary & 31 & 23.8 \\
\cline { 2 - 4 } & Graduate and Above & 13 & 10.0 \\
\hline Monthly Income (BDT) & $<10000$ & 71 & 54.6 \\
\cline { 2 - 4 } & $10001-20000$ & 51 & 39.2 \\
\cline { 2 - 4 } & $>20000$ & 8 & 6.2 \\
\hline
\end{tabular}

\section{Knowledge of the respondents on unsafe abortion}

A large amount of the respondents $(83.3 \%)$ knew about unsafe abortion and few of them (16.7\%) did not know. The majority of the respondents $(83.1 \%)$ knew about the complications of unsafe abortion and $16.9 \%$ did not know. $100 \%$ of the respondents indicated hemorrhage as a complication of unsafe abortion., While $58.5 \%$ were sepsis, $42.3 \%$ uterine perforation, $27.7 \%$ genital tract injury, $12.3 \%$ renal flare, ad only $8.5 \%$ answered for septicemia. Most of the respondents (79.2\%) knew that unsafe abortion may cause death; only $20.8 \%$ did not know the answer. Nearly two third of the respondents $(63.8 \%)$ did not know about any rules and regulation regarding safe abortion and more than one third of them $(36.2 \%)$ knew it previously. Among of the respondents majority (64.6\%) knew about the risk factors of abortion and why $35.4 \%$ did not know. Most of the respondents $(81.5 \%)$ did not know out the types of abortion and only few of them $(18.5 \%)$ knew. The majority of them $(96.2 \%)$ perceived thought was "woman should avoid unsafe abortion" and only $3.8 \%$ did not think so. The findings also show that the greater portion of the respondents $(90.8 \%)$ got the information about from television followed by $51.5 \%$ radio and friends, $36.9 \%$ family and $30.8 \%$ magazine respectively.

Table-2: Knowledge of the respondents on unsafe abortion

\begin{tabular}{|c|c|c|c|}
\hline Variable & & Frequency & Percent $(\%)$ \\
\hline \multirow{2}{*}{ Knowledge of unsafe abortion } & Yes & 108 & 83.3 \\
\hline & No & 22 & 16.7 \\
\hline \multirow[t]{2}{*}{ Knowledge on complication of unsafe abortion } & Yes & 112 & 83.1 \\
\hline & No & 18 & 16.9 \\
\hline \multirow[t]{6}{*}{ Knowledge on possible complication } & Sepsis & 76 & 58.5 \\
\hline & Septicemia & 11 & 8.5 \\
\hline & Hemorrhage & 90 & 100 \\
\hline & Renal failure & 16 & 12.3 \\
\hline & Uterine perforation & 55 & 42.3 \\
\hline & Genital tract injury & 36 & 27.7 \\
\hline \multirow[t]{2}{*}{ Knowledge on fatality of unsafe abortion } & Yes & 103 & 79.2 \\
\hline & No & 27 & 20.8 \\
\hline \multirow{2}{*}{$\begin{array}{l}\text { Knowledge on the rules and regulation regarding safe } \\
\text { abortion }\end{array}$} & Yes & 47 & 36.2 \\
\hline & No & 83 & 63.8 \\
\hline \multirow[t]{2}{*}{ Knowledge on risk factors of abortion } & Yes & 84 & 64.6 \\
\hline & No & 46 & 35.4 \\
\hline \multirow[t]{2}{*}{ Knowledge on type of abortion } & Yes & 24 & 18.5 \\
\hline & No & 106 & 81.5 \\
\hline \multirow[t]{2}{*}{ Knowledge of avoidance of unsafe abortion } & Yes & 125 & 96.2 \\
\hline & No & 5 & 3.8 \\
\hline
\end{tabular}




\section{Association between knowledge on unsafe abortion} and Socio-demographic characteristics

According to study findings revealed that a highly significant association found between knowledge on unsafe abortion and educational qualification of the respondents ( $\mathrm{p}$ value $=$. 001). There was a highly significant association between knowledge of unsafe abortion and monthly income of the respondents $(\mathrm{P}$ value $=$.004).

Table-3: Association between knowledge of unsafe abortion and socio demographic characteristics of the respondents

\begin{tabular}{|l|l|l|l|l|}
\hline Variables & Qualifications & Yes & No & $\mathbf{X}^{\mathbf{2}}(\mathbf{p})$ \\
\hline Qualifications & Illiterate & 8 & 11 & \multirow{2}{*}{$.44(.001)$} \\
\cline { 2 - 4 } & Primary & 32 & 6 & \\
\cline { 2 - 4 } & Secondary & 25 & 4 & \\
\cline { 2 - 4 } & Higher Secondary & 30 & 1 & \\
\cline { 2 - 4 } & Graduate and Above & 13 & 0 & \\
\hline Monthly Income & $<10000$ & 53 & 18 & \multirow{3}{*}{$.48(.004)$} \\
\cline { 2 - 4 } & $10001-20000$ & 47 & 4 & \\
\cline { 2 - 4 } & $>20000$ & 8 & 0 & \\
\hline
\end{tabular}

\section{Discussion}

From the total of 130 reproductive aged women involved in the study, $66.9 \%, 27.7 \%$ and $5.4 \%$ of the respondents belonged to age group of 15-30 years, 31-45 years and 46-60 years respectively with mean age $29.22 \pm 8.215$ years. This finding was nearly similar with Zambian study where $49 \%$ were belonged to age group 15-24 years and 33\% were 25-33 Years [15]. Most of them $(84.6 \%)$ were married and few of them $(15.4 \%)$ of were unmarried. This finding is different from other studies $[13,14]$. In previous studies found $13.1 \%$ to $18.6 \%$ married and $81.4 \%$ were married [13].

Of the respondents (29.2\%) educational qualification level was primary, $23.8 \%$ higher secondary, $22.3 \%$ secondary, $10 \%$ was graduating and above and only $14.6 \%$ found to be illiterate. This finding nearly similar to an African study, where 33\% respondents were primary education qualification [15]. A great portion of the respondents (54.6\%) monthly income was BDT <10000, 39.2\% BDT 10001-20000 and only $6.2 \%$ of their income were BDT $>20000$. This finding is nearly similar with previous Ethiopian Study where found $71.6 \%$ had monthly income $<600$ Ethiopian Birr [14].

A large amount of the respondents $(83.3 \%)$ knew about unsafe abortion and few of them $(16.7 \%)$ did not know. In previous study found that $80.3 \%$ respondent knew unsafe abortion is a major problem today [14]. The majority of the respondents $(83.1 \%)$ knew about the complications of unsafe abortion and $16.9 \%$ did not know. These findings similar with other study [16]. In a South-Asian study, where majority respondents answered unsafe abortion may lead death, hemorrhage, uterine infection and sub-fertility [16].

$100 \%$ of the respondents indicated hemorrhage as a complication of unsafe abortion, while $58.5 \%$ were sepsis, $42.3 \%$ uterine perforation, $27.7 \%$ genital tract injury, $12.3 \%$ renal failure, ad only $8.5 \%$ answered for septicemia. This finding differed from previous study [17]. Der and colleagues study on knowledge of unsafe abortion among 340 youth in Ghana. They found that 99.4\% respondent aware about complication of unsafe abortion. Among them, $16.5 \%$ severe bleeding per vagina, $0.9 \%$, anemic $0.9 \%$, infertility $8.2 \%$, uterine reputure $1.8 \%$, and genital tract infection were $0.9 \%$ [17].

Most of the respondents $(79.2 \%)$ knew that unsafe abortion may cause death; only $20.8 \%$ did not know the answer. This finding varies in others studies, $89 \%$ to $96.6 \%[12,16]$. Perera and Abeysena conducted a study on knowledge and attitude on unsafe abortion among 1575 undergraduate students in Sri Lanka, the majority of the respondents (89\%) answered abortion may cause of death [16].

Nearly two third of the respondents $(63.8 \%)$ did not know about any rules and regulation regarding safe abortion and more than one third of them (36.2\%) knew it previously. This finding contradicts with other studies where varies from $57.3 \%$ to $71.4 \%$ [12, 14]. Mekonnen and Wubneh studied on 633 female students of private colleges in the Gondar City in North Ethiopia regarding knowledge, attitude on safe abortion. Their study findings described $71.4 \%$ has knowledge of abortion law [14]. Among of the respondents majority $(64.6 \%)$ knew about the risk factors of abortion and $35.4 \%$ did not know. This finding lined with a Nigerian Study where university female students were aware about the risks associated with unsafe abortion [18]. Most of the respondents $(81.5 \%)$ did not know out the types of abortion and only few of them (18.5\%) knew. In a Lao DPR study found that $12.5 \%$ adolescents knew that abortion can perform by medication/drugs [19]. The majority of them $(96.2 \%)$ perceived thought was "woman should avoid unsafe abortion" and only 3.8\% did not think so. In another study found that $71.0 \%$ female respondent's positive attitude towards having to access to safe abortion services in Lao PDR [19]. 
The findings also show that the greater portion of the respondents $(90.8 \%)$ got the information about from television followed by $51.5 \%$ radio and friends, $36.9 \%$ family and $30.8 \%$ magazine respectively. This finding contradicts from previous study where $31 \%$ of electronic media, $26 \%$ from friends, and $4.6 \%$ from print media [17] (Appendix).

According to study findings revealed that a highly significant association found between knowledge on unsafe abortion and educational qualification of the respondents $(\mathrm{p}$ value $=.000)$. There was an association found between knowledge on safe abortion and respondent's educational qualification [14]. In a previous study by Mekonnen and Wubneh found that students in the age group of 25 and up were 2.79 times more likely than those in the age group of 18-19 to have strong knowledge of safe abortion [14].

There was a highly significant association between knowledge of unsafe abortion and monthly income $(\mathrm{P}=.004)$ and qualification $(\mathrm{P}$ value $=.001)$ of the respondents $(\mathrm{P}$ value $=.004)$. This finding is similar in previous studies [20]. In Bangladesh female also worked besides male for the solvency of the family. Due to hard labor this variables are strongly significant.

\section{Conclusions}

Much more effort should be made on information, education and communication of awareness and practice of modern contraceptives to decrease unintended pregnancy and abortion cases. In addition, work should be done at the level of health post and health centers to enhance awareness and practice cost and consequences of abortion on women's health. Furthermore, studies exploring the positive attitudepractice gap should be done on women of abortion and rape prevalence to see the cause and effect relationship clearly. Although the knowledge and awareness are good, more awareness regarding abortion is required this can be achieved by implementing aggressive health education and intensive program for all women and men in the community through the health worker.

\section{Limitation of the Study}

It was a purposive non-randomized crosssectional study done only in a district of Bangladesh. It is a cross-sectional study feedback is not taken from the pertipants. Lastly, as a self finance study, the budget and other resources were limited.

\section{REFERENCES}

1. World Health Organization. (2020). Abortion. 2020. Retrieved on 26 March 27, 2021 from https:/ /www.who.int/health-topics/abortion\#tab=tab_1

2. Gebremedhin, M., Semahegn, A., Usmael, T., \& Tesfaye, G. (2018). Unsafe abortion and associated factors among reproductive aged women in SubSaharan Africa: a protocol for a systematic review and meta-analysis. Systematic reviews, 7(1), 1-5.
4 Singh, S., Remez, L., Sedgh, G., Kwok, L., \& Onda, T. (2018). Abortion worldwide 2017: uneven Progress and unequal AccessAbortion worldwide 2017: uneven Progress and unequal Access.

5 Rana, J., Sen, K. K., Sultana, T., Hossain, M. B., \& Islam, R. M. (2019). Prevalence and determinants of menstrual regulation among ever-married women in Bangladesh: evidence from a national survey. Reproductive health, 16(1), 1-9.

5. Sohel, F. A., Jahan, S., Russel, S., \& Zafreen, F. (2018). Socio-demographic Profile of Abortion Cases attending at a Tertiary Level Hospital. Journal of Armed Forces Medical College, Bangladesh, 14(2), 200-202.

6. Afiaz, A., Biswas, R. K., Shamma, R., \& Ananna, N. (2020). Intimate partner violence (IPV) with miscarriages, stillbirths and abortions: Identifying vulnerable households for women in Bangladesh. PloS one, 15(7), e0236670.

7. National Institute of Population Research and Training (NIPORT), International Centre for Diarrhoeal Disease Research, Bangladesh (ICDDR, B), \& MEASURE Evaluation. (2017). Bangladesh Maternal Mortality and Health Care Survey 2016: Preliminary Report.

8. Ahmed, T., \& Khan, N.J. (2021). OPINION: Young people key to safe and legal abortion in Bangladesh. 2020. Retrieved on March 28, 2021 from https://news.trust.org/item/202 00928083717-3j9pt/

9. Kishun, J., \& Kumar, A. (2020). A Model for Predicting Unsafe Induced Abortion among Women in India. Indian Journal of Community Health, 32(3).

10. Yokoe, R., Rowe, R., Choudhury, S. S., Rani, A., Zahir, F., \& Nair, M. (2019). Unsafe abortion and abortion-related death among 1.8 million women in India. BMJ global health, 4(3), e001491.

11. Guttmacher Institute. (2021). Menstrual Regulation and Unsafe Abortion in Bangladesh. 2021. Retrieved on March 29, 2021 fromhttps://www.guttmacher.org/sites/default/files/ factsheet/menstrual-regulation-unsafe-abortionbangladesh.pdf

12. Abiola, A. H., Oke, O. A., Balogun, M. R., Olatona, F. A., \& Adegbesan-Omilabu, M. A. (2016). Knowledge, attitude, and practice of abortion among female students of two public senior secondary schools in Lagos Mainland Local Government Area, Lagos State.

13. Geleto, A., \& Markos, J. (2015). Awareness of female students attending higher educational institutions toward legalization of safe abortion and associated factors, Harari Region, Eastern Ethiopia: a cross sectional study. Reproductive health, 12(1), $1-9$.

14. Mekonnen, B. D., \& Wubneh, C. A. (2020). Knowledge, Attitude, and Associated Factors towards Safe Abortion among Private College Female Students in Gondar City, Northwest 
Ethiopia: A Cross-Sectional Study. Advances in preventive medicine, 2020.

15. Cresswell, J. A., Schroeder, R., Dennis, M., Owolabi, O., Vwalika, B., Musheke, M., ... \& Filippi, V. (2016). Women's knowledge and attitudes surrounding abortion in Zambia: a crosssectional survey across three provinces. BMJ open, 6(3).

16. Perera, U., \& Abeysena, C. (2018). Knowledge and attitudes on unsafe abortion among the undergraduates of state universities in Western Province, Sri Lanka. Journal of the College Community Physicians of Sri Lanka, 24(2).

17. Der, E.M., Ndego, S.R., Larbi, O.S., Opoku, A., Nakong, V. (2019). The Knowledge of Unsafe Abortion among the Youth: The Case of Tamale Metropolis in the Northern Region of Ghana.
International Journal of Medical Science and Clinical Invention, 6(7): 4522-4529.

18. Cadmus, E. O., \& Owoaje, E. T. (2011). Knowledge about complications and practice of abortion among female undergraduates in the university of Ibadan, Nigeria. Annals of Ibadan postgraduate medicine, 9(1), 19-23.

19. Vongxay, V., Chaleunvong, K., Essink, D. R., Durham, J., \& Sychareun, V. (2020). Knowledge of and attitudes towards abortion among adolescents in Lao PDR. Global Health Action, 13(sup2), 1791413.

20. Dhar, G. (2017). Knowledge, attitude and associated factors towards safe abortion among female students of kebribayah town of Somali region, Ethiopia. International Journal of Health Sciences and Research, 7(10).

Cite This Article: Sufia Khatun et al (2021). Awareness of Unsafe Abortion among the Reproductive Age Women in a Tertiary Level Hospital in Sylhet, Bangladesh. East African Scholars Multidiscip Bull, 4(3), 22-27. 